\title{
Interrelações entre a profundidade do solo e o substrato geológico na região centro-leste de Minas Gerais
}

\author{
Agna Almeida Menezes ${ }^{1}$, Liovando Marciano da Costa², Ana Maria Souza dos Santos Moreau ${ }^{1 *}$, \\ Mauricio Santana Moreau ${ }^{1}$
}

\begin{abstract}
RESUMO
O estudo das interrelações entre profundidade do solo e o substrato geológico de uma área é importante para a compreensão da gênese do solo e seus atributos físicos, químicos e morfológicos, constituindo-se em importante ferramenta para avaliar a influência das características do material de origem no grau de intemperismo e, consequentemente, na profundidade do perfil do solo. Com o objetivo de estabelecer essas relações, levantaram-se informações detalhadas quanto aos aspectos geológicos, como: litotipos, constituição, minerais principais, textura, granulação e cor das rochas das regiões de Cocais, Rio Doce, Sabinópolis, Virginópolis e Santa Bárbara, em Minas Gerais, bem como suas classes de solos e a profundidade de aparecimento dos horizontes B/C ou C. Essas relações foram obtidas por meio de um sistema geográfico de informações e de uma análise estatística simples entre os litotipos e profundidade dos solos. A partir dessas relações foi possível agrupar os valores médios de profundidade do solo de acordo com o material de origem, propiciando uma análise de agrupamento pelo método de minimização da variância (CLUSTERMV-SAEG), utilizando-se a distância euclidiana média. Os resultados indicam que materiais bandados em relação a rochas maciças estão relacionados com perfis mais profundos, da mesma forma que rochas com granulação mais grossa têm maior capacidade de intemperização e, portanto, estão relacionadas com solos mais profundos.
\end{abstract}

Palavras-chave: Intemperismo, pedogênese, relações solo-geologia.

\section{ABSTRACT \\ Interelation between depth of soil and geological substrate in the East Center of Minas Ge- rais State, Brazil}

The study of interrelation between soil depth and geological substrate of a place is important to understand the soil genesis and the physical, chemical and morphological attributes of the soil. This is an important tool to evaluate the influence of the parent material characteristics in the weathering and its influence in the depth of a soil profile. The geological data of different rocks were gathered for a studied site. The rock type, its essential minerals, texture and color of the rocks were obtained in the municipalities of Cocais, Rio Doce, Sabinópolis, Virginópolis and Santa Bárbara in the eastern part of the state of Minas Gerais. The soil classes and their parent material data were also examined. Emphasis was given the depth of appearance of the top of the $\mathrm{C}$ or B/C horizons for each soil class found in the study sites. The information was obtained by using the data from the geographical information system associated to a simple statistical analysis which relates lithotypes to soil depth. It was possible to group the average data for each soil class

Recebido para publicação em 11/01/2010 e aprovado em 14/09/2011

${ }^{1}$ Engenheiros-Agrônomos, Doutores. Departamento de Ciências Agrárias e Ambientais, Universidade Estadual de Santa Cruz, Rodovia Ilhéus/Itabuna, Km 16, 45650-000, Ilhéus, BA, Brasil. agna@uesc.br, amoreau@uesc.br,mmoreau@uesc.br,* Autora para correspondência

${ }^{2}$ Engenheiro-Agrônomo, Ph. Doctor. Departamento de Solos, Universidade Federal de Viçosa, Av. Peter Henry Rolfs, s/n, Campus Universitário, 36570-000, Viçosa, MG, Brasil. liovandomc@yahoo.com.br 
and its parent material. It was performed a cluster analysis based on the method of minimum variance. It was used the Euclidian average distance. The results indicated that foliated rocks in relation to a non foliated are related deeper soils, the same way, rocks with coarse grained could accelerate the weathering and form deeper soils than the fine grained rocks.

Key words: Soil-geology relation, pedogenesis, weathering.

\section{INTRODUÇÃO}

Autores como Azolin et al. (1975); Rodrigues \& Klamt (1978); Lepsch et al. (1977); Perez Filho (1980); Uberti \& Klamt (1984); Berg et al. (1987); Coelho et al. (1994), Motta et al. (2002), dedicaram-se a estudos sobre a relação sologeomorfologia, buscando compreender a dinâmica e a distribuição dos solos na paisagem.

No entanto, observa-se que pesquisas relacionadas com os aspectos geológicos, no que se refere à textura, granulação, estrutura e sua influência na profundidade dos solos são muito escassas e, algumas vezes, contestáveis, por analisarem um único aspecto. Nessa temática, Licht (1998) afirma que uma rocha finamente granulada é relativamente permeável e será rapidamente intemperizada, por causa da grande superfície específica dos grãos, sendo esta afirmativa aplicada para rochas sedimentares clásticas. Para rochas ígneas e metamórficas, as de granulação de média a grossa, o manto de intemperismo é mais espesso, certamente por disporem de 'microcanais', ao longo dos contatos dos grãos, por onde ocorre a percolação das soluções, o que não acontece com as ígneas de granulação fina, que mostram-se pouco permeáveis.

Bigarella et al. (1994), ao estudarem a relação entre a espessura do manto de alteração e os aspectos geológicos, concluíram que as características do manto de granito são diferentes das daquele formado de gnaisse e que a granulação e disposição das camadas são os principais fatores responsáveis por essa diferenciação. Segundo os autores, na região da Guanabara, os gnaisses de textura muito fina estão recobertos por um espesso manto de alteração, enquanto os gnaisses e granitos de granulação grosseira resistem mais à ação do intemperismo químico. A maior ou menor espessura do manto de alteração é, assim, atribuída à granulação dos minerais, sem enfatizar a massividade e o bandamento encontrados no granito e gnaisse, respectivamente.

Dejou et al. (1971), citados por Marques (1998), ao estudar dois sítios de ocorrência de micaxisto no Maciço Central Francês, que diferiam exclusivamente pelo mergulho da xistosidade, observaram que o manto intemperizado do perfil com xistosidade subvertical apresentava uma espessura aproximadamente duas vezes maior que a do perfil desenvolvido no local onde a xistosidade é subhorizontal.

Way (1973) avançou, ao relacionar a profundidade do solo à litologia, no que se refere ao grau de massividade, foliação e estratificação. Assim, segundo o autor, solos formados de granitos são relativamente rasos, por causa da natureza maciça e resistência uniforme ao intemperismo. Em rochas com foliação, como os gnaisses, a diferença de resistência ao intemperismo propicia solos mais profundos, silto-arenosos ou argilo-arenosos, portanto, mais susceptíveis à erosão. Rochas estratificadas, como os argilitos, siltitos, originam solos normalmente rasos, siltosos e que contêm muitos fragmentos de rocha dentro do subsolo.

Assim, apesar de toda a ênfase dada aos fatores climáticos e àqueles relacionados com a topografia e drenagem na intensidade de atuação do processo de intemperismo, não se pode ignorar a influência dos atributos dos litotipos na profundidade dos solos e, ou, do manto de alteração. Na presente pesquisa, a abordagem refere-se àqueles atributos intrínsecos às rochas e aos minerais.

Objetivou-se, portanto, conhecer as interrelações entre a profundidade do solo e o substrato geológico, visto ser de suma importância na predição, tanto das fragilidades ambientais relacionadas com o potencial erosivo do solo, como da profundidade efetiva para produção agrícola e dos atributos dos solos herdados do material de origem.

\section{MATERIAL E MÉTODOS}

A área de estudo localiza-se, em sua maioria, entre os paralelos $18^{\circ}$ a $20^{\circ}$ de latitude Sul e entre os meridianos $42^{\circ}$ a $44^{\circ}$ a oeste de Greenwhich. Neste quadrante, registramse unidades pertencentes às províncias geotectônicas do São Francisco (cráton), Mantiqueira e as faixas de dobramento Araçuaí e Brasília (Pedrosa-Soares et al., 1994).

No mapeamento geológico, elaborado pelo SEME/ COMIG/CPRM (Oliveira \& Leite, 2000), foram descritas, para o quadrante em estudo, em escala de 1:100.000, uni- 
dades pertencentes, em sua grande maioria, ao PréCambiano, sendo identificadas como pertencentes aos supergrupos Rio das Velhas e Minas e aos grupos Juiz de Fora, Paraíba, Espinhaço, Itacolomi e Macaúbas. A litologia é representada por rochas arqueanas plutônicas gnaissificadas e rochas metassedimentares proterozoicas.

Os litotipos objetos desta pesquisa foram: Complexo Basal (unidade 1), Formação São Tomé, Suíte Borrachudos Granito Açucena (Ipatinga e Coronel Fabriciano), Granito Açucena (Dom Cavati), Complexo Mantiqueira e Tonalito Bom Jesus. A descrição litológica de cada grupo foi feita com base nos trabalhos de levantamento geológico de Almeida e Litwinski (1984), Soares Filho et al. (1986), Dossin et al. (1990), Brandalise (1991), Ribeiro (1997), Brandalise e Heineck (1999), Oliveira \& Leite (2000), Ribeiro (2000), Signorelli (2000) e Silva (2000).

Para avaliar a interrelação entre os litotipos e a profundidade dos solos, foram levantadas informações de 87 perfis de solo das regiões de Cocais, Rio Doce, Sabinópolis, Virginópolis e Santa Bárbara, todos municípios do Estado de Minas Gerais. Para as quatro primeiras regiões, os dados constam do relatório parcial do levantamento semidetalhado de solos de áreas da Empresa Cenibra Nipocelulose S.A. Aqueles referentes à região de Santa Bárbara foram obtidos por Amaral (1999). Os perfis estudados estão inseridos nas classes Latossolo, Cambissolo e Argissolo, totalizando 51, 30 e 6 unidades, respectivamente.

Os Latossolos são solos constituídos por material mineral, com horizonte B latossólico imediatamente abaixo de qualquer um dos tipos de horizonte diagnóstico superficial; apresentam avançado estágio de intemperismo e, consequentemente, caracterizam-se por serem solos profundos, com pouca diferenciação dos seus horizontes e baixos teores, ou virtual ausência, de minerais primários facilmente alteráveis. A classe dos Argissolos compreende solos que têm como característica principal a presença de horizonte B textural imediatamente abaixo de A ou E, normalmente com argila de atividade baixa e ocorrência de argila de atividade alta, conjugada com saturação por bases baixa ou com caráter alítico. A classe dos Cambissolos apresenta, como conceito central, a de solos em estágio intermediário de intemperismo, isto é, que não sofreram alterações físicas e químicas muito avançadas, assim, em geral, não são muito profundos e com teores relativamente elevados de minerais primários facilmente intemperizáveis (Embrapa, 2006)

Nos trabalhos de levantamento de solos realizados por Cenibra e Amaral (1999), os perfis de solos foram descritos e coletados segundo Lemos e Santos (1996) e classificados pelo Sistema Brasileiro de Classificação de Solos (Embrapa, 1997).
Do conjunto de perfis somente 38 foram selecionados, porque apresentavam, na descrição, horizontes B/C e,ou, C, sendo 12 Latossolos, 23 Cambissolos e 3 Argissolos. Cada perfil foi localizado no mapa geológico e seu material de origem encontra-se descrito nas Tabelas 1,2 e 3 .

O agrupamento inicialmente feito por classes de solo mostrou-se mais apropriado, tendo em vista que os atributos da classe são reflexos das condições de clima, topografia e material de origem, assim como a profundidade do solum $(\mathrm{A}+\mathrm{B})$, que é um atributo utilizado para fins de classificação.

Objetivando avaliar qual material de origem ou litotipo estava relacionado com os solos mais rasos, realizou-se uma estatística simples para os litotipos que apresentaram pelo menos duas observações (Tabela 4).

As interações entre as unidades de mapeamento de solos e a litologia foram estabelecidas, cruzando-se as informações dos mapas, utilizando-se para tanto o programa GMAP (Sparovek et al., 1993).

Os litotipos foram agrupados de acordo com a profundidade do solo pelo método de minimização da variância (CLUSTERMV - SAEG, 2007), utilizando-se a distância euclidiana média. Essa possibilidade de formação de grupos permitiu uma análise de agrupamentos.

\section{RESULTADOS E DISCUSSÃO}

O intemperismo químico intenso de rochas e sedimentos, obviamente atrelado à alta precipitação pluviométrica, temperatura e relevo, que favoreçam a lixiviação dos elementos dissolvidos, favorece a formação de Latossolos. Assim, em comparação com outras classes, os latossolos são normalmente muito profundos, sendo a espessura do solum raramente inferior a um metro (Embrapa, 2006).

Neste estudo, para os Latossolos, os horizontes B/ $\mathrm{C}$ e,ou, $\mathrm{C}$ aparecem a uma profundidade média de 158,0 $\mathrm{cm}$, com um coeficiente de variação (CV) de $37,5 \%$. Os Cambissolos apresentaram uma profundidade média de 107,5 cm, com um CV de 37 \%. Já os Argissolos registraram uma profundidade média de $116,7 \mathrm{~cm}$, com um CV de $11,7 \%$.

Portanto, a profundidade de aparecimento do horizonte $\mathrm{B} / \mathrm{C}$ ou $\mathrm{C}$ observou a seguinte sequência: Latossolo > Argissolo > Cambissolo. Entretanto, tal ordem foi diferente para o coeficiente de variação que registrou: Latossolo > Cambissolo > Argissolo, divergindo dos dados da Embrapa (2006), que observou profundidade bastante variável para este último.

Analisando-se a Tabela 4, vê-se que os valores médios de profundidade do topo dos horizontes B/C ou $\mathrm{C}$ podem ser agrupados de acordo com o material de origem. Independentemente da classe de solo, observa-se 
que os solos mais rasos estão associados à Suíte Borrachudos, Granito Açucena (Coronel Fabriciano e Ipatinga), com 91,45 cm. Com amplitude entre 120,5 e 137,33 $\mathrm{cm}$, os solos estão associados ao Tonalito Bom Jesus, Complexo Basal (unidade 1) e Granito Açucena (Dom Cavati). Os solos mais profundos, cujos horizontes $\mathrm{B} / \mathrm{C}$ ou C aparecem a 153,6 e 175,3 cm, estão associados à Formação São Tomé e ao Complexo Mantiqueira, respectivamente.

O Granito Açucena da Suíte Borrachudos distribui-se em duas faixas paralelas, que se interligam no limite norte da folha Coronel Fabriciano e adentra para a Folha Ipatinga e Dom Cavati, formando um maciço. Três tipos petrográficos de granito foram individualizados e denominados como granito equigranular foliado, granito porfirítico foliado e gnaisse granitoide. Nas folhas Coronel Fabriciano e Ipatinga, predominam o equigranular foliado e, em Dom Cavati, o porfirítico foliado e o gnaisse granitoide.

Os resultados da análise de agrupamentos estão representados na Figura 1 e Tabela 5, em que também é apresentada a distribuição dos membros de cada grupo, de acordo com a profundidade de aparecimento dos horizontes B/C ou C, a média e a variação de cada grupo, bem como sua descrição.

Para o Grupo 1, solos mais rasos, o material de origem predominante é o Granito Açucena. Esta unidade foi devidamente descrita nas folhas Coronel Fabriciano e Ipatinga. É formada por granito equigranular foliado; sua composição, apesar de granítica, como a folha Dom Cavati, difere desta, por apresentar cristais da mesma ordem de grandeza, com granulação de fina a média e com quartzo, plagioclásio, feldspato e biotita, como minerais essenciais, e textura granoblástica, ou seja, os minerais granulares não têm orientação dominante.

Analisando exclusivamente as características deste litotipo ou material de origem como único fator responsável pela profundidade do solo, percebe-se que a intermperização e o consequente aprofundamento do solo estão impossibilitados, tanto pela composição mineralógica com minerais essenciais predominantes resistentes ao intemperismo (granito leucocrático), como pela granulação (fina a média) e pela homogeneidade no tamanho dos cristais (equigranular). Para rochas ígneas e metamórficas, de granulação de média a grossa, a presença de 'microcanais' ao longo dos contatos dos grãos facilita a percolação das soluções, o que não acontece com as ígneas finas, que mostram-se pouco permeáveis (Licht, 1998). Além disso, como a foliação deste granito é sub-horizontal, há uma dificuldade maior na percolação de água no corpo rochoso e, portanto, a intemperização é menor.

Em contraposição, o Granito Açucena da Folha Dom Cavati nos Grupos 2 e 3, originou solos mais profundos que os do Grupo 1. Neste caso, vale ressaltar, que os litotipos do Granito Açucena são granitos porfiríticos, nos quais a presença de cristais de dimensões diferenciadas, associada à textura de média a grosseira e à forte foliação desta rocha, potencializa a ação dos agentes intempéricos, resultando na formação de solos mais profundos que aqueles associados ao granito equigranular. O outro litotipo, descrito na folha Dom Cavati, que compõe o Granito Acuçena, é o gnaisse granitoide de composição granítica e tonalítica, com a presença do quartzo, feldspato, biotita e hornblenda como minerais essenciais, e granulação de média a grossa, com forte foliação. Essas características in-

Tabela 1 - Profundidade média de ocorrência do topo do B/C ou C para a classe Latossolos de acordo com a região, litotipo e folha

\begin{tabular}{lccc}
\hline Região & Litotipo & Folha & $\begin{array}{c}\text { Profundidade média } \\
\text { horizonte B/C ou C } \\
\text { (cm) }\end{array}$ \\
\hline \multicolumn{1}{c}{ Classe Latossolo } \\
\hline Cocais & Suíte Borrachudos Granito Açucena & Ipatinga & 128 \\
Cocais & Suíte Borrachudos Granito Açucena & Ipatinga & 115 \\
Cocais & Suíte Borrachudos Granito Açucena & Ipatinga & 95 \\
Cocais & Suíte Borrachudos Granito Açucena & Coronel Fabriciano & 140 \\
Cocais & Complexo Mantiqueira & Ipatinga & 156 \\
Rio Doce & Complexo Mantiqueira & Dom Cavati & 230 \\
Rio Doce & Formação São Tomé & Dom Cavati & 260 \\
Rio Doce & Formação São Tomé & Dom Cavati & 260 \\
Sabinópolis & Super Grupo Minas & Radar & 105 \\
Virginópolis & Complexo Basal & Marilac & 110 \\
Virginópolis & Complexo Basal & Marilac & 137 \\
Santa Bárbara & Metabasito & Itabira & 160 \\
\hline Média & & & 158 \\
\hline CV $(\%)$ & & & 37,5 \\
\hline
\end{tabular}


tensificam os processos intempéricos físicos e químicos de hidrólise, justificando a ocorrência de solos mais profundos nos Grupos 2 e 3.

Os resultados indicam que, para os granitos, a diferença na profundidade dos solos deve-se ao grau de heterogeneidade no tamanho dos cristais $(3,3$ - $10 \mathrm{~mm})$ e à textura, sendo que, rochas com assembleias mineralógicas de tamanhos variados e textura de grosseira a média, propiciaram a formação de mantos de alterações mais profundos que as equigranulares.
O Grupo 4, que apresenta os solos mais profundos formou-se a partir dos litotipos que compõem a Complexo Basal (unidade 1) da Folha Marilac, Complexo Mantiqueira e a Formação São Tomé, ambos da Folha Dom Cavati.

De modo geral, tanto o Complexo Basal (unidade 1), da Folha Marilac, como o Complexo Mantiqueira, da Folha Dom Cavati, apresentam litotipos semelhantes. Segundo Ribeiro (1997 e 2000), são gnaisses bandados de composição tonalítica, tendo como componentes essenciais quartzo, plagioclásio, feldspato, biotita e,ou, hornblenda

Tabela 2 - Profundidade média de ocorrência do topo do B/C ou C para a classe Cambissolos de acordo com a região, litotipo e folha

\begin{tabular}{|c|c|c|c|}
\hline Região & Litotipo & Folha & $\begin{array}{c}\text { Profundidade média } \\
\text { do horizonte } \mathrm{B} / \mathrm{C} \text { ou } \mathrm{C} \\
(\mathrm{cm})\end{array}$ \\
\hline \multicolumn{4}{|c|}{ Classe Cambissolo } \\
\hline Cocais & Suíte Borrachudos Granito Açucena & Ipatinga & 62 \\
\hline Cocais & Suíte Borrachudos Granito Açucena & Ipatinga & 85 \\
\hline Cocais & Suíte Borrachudos Granito Açucena & Ipatinga & 70 \\
\hline Cocais & Suíte Borrachudos Granito Açucena & Coronel Fabriciano & 80 \\
\hline Cocais & Suíte Borrachudos Granito Açucena & Ipatinga & 60 \\
\hline Cocais & Suíte Borrachudos Granito Açucena & Ipatinga & 65 \\
\hline Rio Doce & Formação São Tomé & Dom Cavati & 118 \\
\hline Rio Doce & Formação São Tomé & Dom Cavati & 100 \\
\hline Rio Doce & Formação São Tomé & Dom Cavati & 135 \\
\hline Rio Doce & Formação São Tomé & Dom Cavati & 90 \\
\hline Rio Doce & Granito Açucena & Dom Cavati & 122 \\
\hline Rio Doce & Granito Açucena & Dom Cavati & 150 \\
\hline Rio Doce & Tonalito Bom Jesus & Dom Cavati & 109 \\
\hline Rio Doce & Complexo Mantiqueira & Dom Cavati & 140 \\
\hline Rio Doce & Complexo Basal (unidade 1) & Marilac & 220 \\
\hline Sabinópolis & Complexo Basal (unidade 1) & Marilac & 148 \\
\hline Sabinópolis & Complexo Basal (unidade 1) & Marilac & 70 \\
\hline Virginópolis & Granito Açucena & Marilac & 140 \\
\hline Virginópolis & Complexo Basal (unidade 1) & Marilac & 158 \\
\hline Virginópolis & Complexo Basal (unidade 1) & Marilac & 68 \\
\hline Santa Barbára & Suíte Borrachudos & Itabira & 82 \\
\hline Santa Barbára & Complexo Santa Bárbara & Itabira & 100 \\
\hline Santa Barbára & Formação Cauê & Itabira & 100 \\
\hline Média & & & 107,47 \\
\hline$\overline{\mathrm{CV}(\%)}$ & & & 37 \\
\hline
\end{tabular}

Tabela 3 - Profundidade média de ocorrência do topo do B/C ou C para a classe Argissolos de acordo com a região, litotipo e folha

\begin{tabular}{lccc}
\hline Região & Litotipo & Folha & $\begin{array}{c}\text { Profundidade média } \\
\text { do horizonte B/C ou C } \\
(\mathbf{c m})\end{array}$ \\
\hline Cocais & Classe Argissolo & \\
Rio Doce & Suíte Borrachudos Granito Açucena & Ipatinga & 106 \\
Rio Doce & Tonalito Bom Jesus & Dom Cavati & 132 \\
\hline Média & Formação São Tomé & Dom Cavati & 112 \\
\hline $\mathrm{CV}(\%)$ & & & 116,7 \\
\hline
\end{tabular}

Rev. Ceres, Viçosa, v. 58, n.6, p. 794-801, nov/dez, 2011 
e granodiorítica, cujos componentes essenciais são: quartzo, plagioclásio e K feldspato, biotita e,ou, hornblenda, geralmente presentes com minerais essenciais quartzo, feldspato e biotita, com granulação de fina a média e textura granoblástica (textura metamórfica, com arranjo dos minerais na forma de grãos, que tendem a ser equidimensionais, poligonizados a lenticulados e orientados, quando dão origem a uma foliação por achatamento de grãos), a nematoblástica (textura metamórfica, caracterizada por minerais de hábito alongado, prismático ou acicular, como os anfibólios e a sillimanita, dispondo-se de forma orientada paralela ou subparalelamente).

Admite-se, portanto, que, por causa do bandamento, estes litotipos são mais facilmente intemperizáveis, originando, assim, solos mais profundos que aqueles originados de granitos, que são rochas maciças. Estes resultados concordam com os de Way (1973), que relacionou a presença de solos mais rasos, quando originados de granitos e profundo manto de alteração, quando o material de origem é o gnaisse. Assim, para o gnaisse, os fatores que potencializam a ação intempérica são o bandamento e a sua inclinação, enquanto, para o granito, por tratar-se de uma rocha maciça, as maiores influências serão da granulação e da textura.

Apesar de apresentarem a mesma composição gnáissica, os solos do Complexo Mantiqueira mostraramse, em média, $45 \mathrm{~cm}$ mais profundos que os do Complexo Basal (Tabela 4). Isso, provavelmente, decorre das intercalações com anfibolito e metagabro e da discordância entre as rochas, aumentando a instabilidade. Por tratar-se de rochas de coloração cinza escuro a esverdeado, textura granoblástica e granulação de média a grossa, originadas de ígneas básicas, como o basalto, bem como pelo baixo percentual em quartzo na sua composição mineralógica, o anfibolito e o metagabro associados ao gnaisse conferiram, ao Complexo Mantiqueira, uma maior vulnerabilidade ao intemperismo, do que a do Complexo Basal.

A Formação São Tomé apresenta composição xistosa, granulação fina, textura lepidoblástica, definida por minerais lamelares, como as micas e as cloritas, dispondo-se

Tabela 4 - Profundidade média do topo do horizonte B/C ou C por litotipo com valor máximo, mínimo e coeficiente de variação

\begin{tabular}{|c|c|c|c|c|c|}
\hline \multirow{2}{*}{ Litotipo } & \multirow{2}{*}{$\mathbf{N}$} & Máximo & Mínimo & Média & \multirow{2}{*}{$\frac{\mathrm{CV}}{\%}$} \\
\hline & & & $(\mathbf{c m})$ & & \\
\hline Complexo Basal (unidade 1) & 7 & 220 & 68 & 130,14 & 41,0 \\
\hline Formação São Tomé & 7 & 260 & 90 & 153,57 & 48,2 \\
\hline $\begin{array}{l}\text { Suíte Borrachudos Granito Açucena } \\
\text { (Ipatinga e Coronel Fabriciano) }\end{array}$ & 11 & 140 & 60 & 91,45 & 30,3 \\
\hline Granito Açucena (Dom Cavati) & 3 & 150 & 122 & 137,33 & 10,3 \\
\hline Complexo Mantiqueira & 3 & 230 & 140 & 175,33 & 27,4 \\
\hline Tonalito Bom Jesus & 2 & 132 & 109 & 120,50 & 13,5 \\
\hline
\end{tabular}

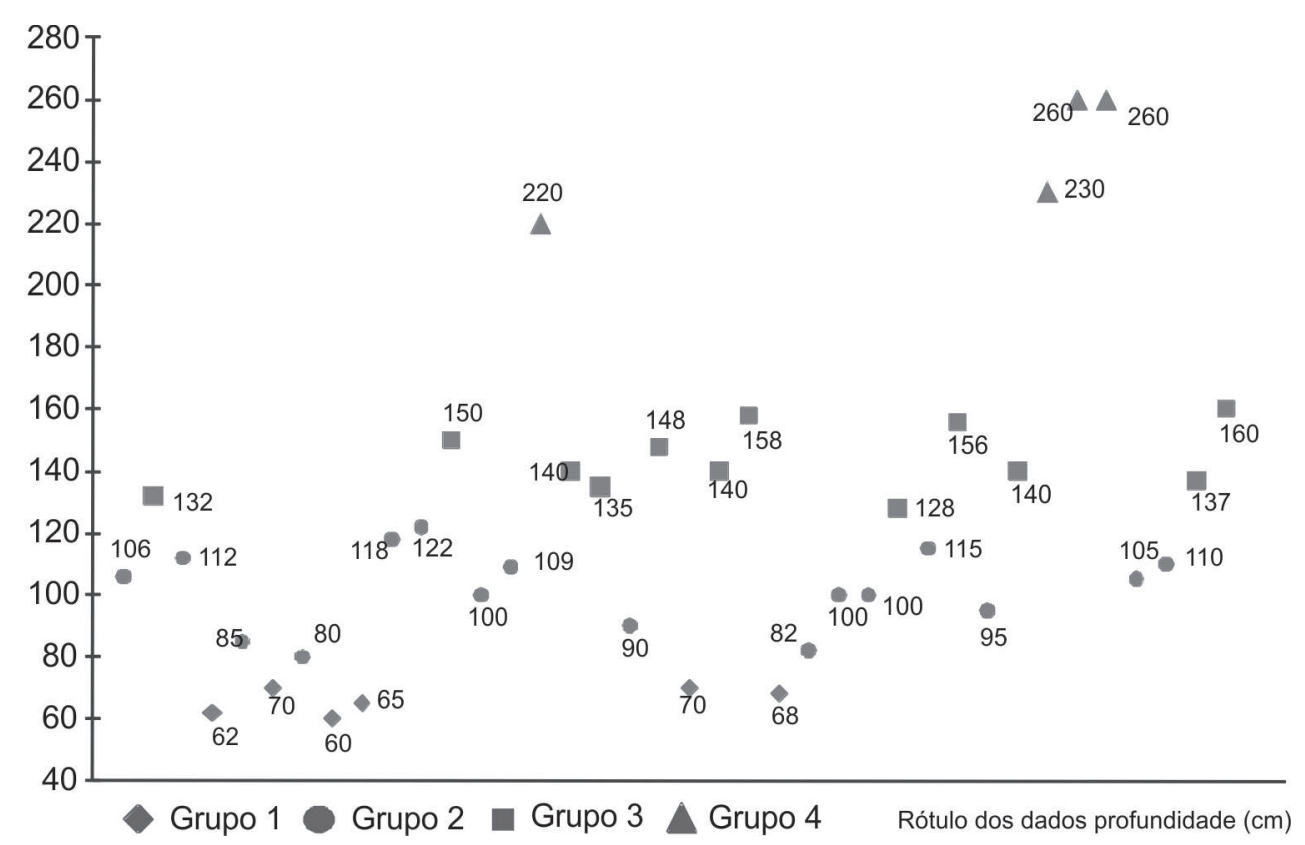

Figura 1 - Distribuição dos perfis de solos por grupo de acordo com a profundidade média de ocorrência do topo do horizonte B/C ou C (grupos definidos por análise de agrupamento para minimização das variâncias). 
Tabela 5 - Descrição litológica de cada grupo com indicação do número de perfis estudados, sua profundidade média e coeficiente de variação

\begin{tabular}{|c|c|c|c|c|}
\hline Grupo & $\mathbf{N}$ & $\begin{array}{c}\text { Média } \\
(\mathrm{cm})\end{array}$ & $\begin{array}{l}\text { CV } \\
(\%)\end{array}$ & Descrição grupo \\
\hline 1 & 6 & 65,83 & 6,4 & $\begin{array}{l}\text { Compõe-se de } 6 \text { Cambissolos, associados a Suíte Borrachudos } \\
\text { Granito Açucena (Ipatinga e Coronel Fabriciano) e ao Complexo } \\
\text { Basal (unidade 1) }\end{array}$ \\
\hline 2 & 16 & 101,82 & 12,5 & $\begin{array}{l}\text { Compõe-se de } 2 \text { Argissolos, } 10 \text { Cambissolos e } 4 \text { Latossolos, } \\
\text { associados, em sua maioria (9), à Formação São Tomé e Granito } \\
\text { Açucena (Dom Cavati), sendo os demais relacionados com Suíte } \\
\text { Borrachudos, Complexo Basal (unidade 1), Complexo Santa Bár- } \\
\text { bara, Formação Cauê, Super grupo Minas e Tonalito Bom Jesus. } \\
\text { Este é o grupo mais diverso. }\end{array}$ \\
\hline 3 & 12 & 143,67 & 7,3 & $\begin{array}{l}\text { Compõe-se de } 1 \text { Argissolo, } 6 \text { Cambissolos e } 5 \text { Latossolos, asso- } \\
\text { ciados aos Complexo Basal (unidade 1), Formação São Tomé, } \\
\text { Granito Açucena (Dom Cavati), Complexo Mantiqueira, } \\
\text { Metabasito e Tonalito Bom Jesus }\end{array}$ \\
\hline 4 & 4 & 242,5 & 8,5 & $\begin{array}{l}\text { Compõe-se de } 1 \text { Cambissolo e } 3 \text { Latossolos, associados ao Com- } \\
\text { plexo Basal (unidade 1), Complexo Mantiqueira e Formação São } \\
\text { Tomé }\end{array}$ \\
\hline
\end{tabular}

subparalelamente. O quartzo, o plagioclásio e a muscovita são os minerais essenciais. Para esta formação, a presença dos xistos finos com estratificação subparalela justifica a profundidade média de $120,5 \mathrm{~cm}$ dos solos formados a partir deste material de origem (Tabelas 4 e 5 ).

\section{CONCLUSÕES}

Considerando-se exclusivamente o material de origem como fator de aprofundamento do perfil de solo, concluise que materiais bandados (gnaisses) resultam em perfis mais profundos em relação aos resultantes de rochas maciças (granitos).

Em rochas maciças, a heterogeneidade no tamanho dos cristais e a granulação de grossa a média propiciaram a ação dos agentes intempéricos, resultando na formação de solos mais profundos;

Nas rochas bandadas, como o gnaisse, a intercalação e discordância com rochas básicas favorecem o intemperismo e potencializam a formação de solos mais profundos.

\section{REFERÊNCIAS}

Almeida FFM \& Litwinski N (1984) Província Mantiqueira Setor Setentrional. In: Almeida FFM \& Hasui Y (Eds). O précambriano do Brasil. São Paulo, Edgard Blucher. p.282-307.

Amaral G (1999) Características químicas e físicas de diferentes classes de solos da Zona Metalúrgica mineira e produtividade de eucalipto. Dissertação de Mestrado. Universidade Federal de Viçosa, Viçosa.111p.

Azolin MAD, Klamt E \& Santos MCC (1975) Relações solo-superfícies geomórficas e material de origem a oeste da depressão central e campanha no Rio Grande do Sul. In: $15^{\circ}$ Congresso Brasileiro de Ciência do Solo, Campinas, Anais, SBCS. p.345-350.
Berg MVD, Lepsch IF \& Sakai E (1987) Solos de planícies aluviais do vale do Ribeira do Iguape: I Padrões de distribuição. Revista Brasileira de Ciência do Solo, 11:305-313.

Bigarella JJ, Becker RD \& Passos E (1994) Estrutura e origem das paisagens tropicais e subtropicais. Intemperismo biológico, pedogênese, laterização, bauxitização e concentração de bens minerais. $1^{\mathrm{a}}$ ed. Florianópolis, Editora da UFSC. 425p.

Brandalise LA (1991) Projeto Barbacena: Folha Ponte Nova SF.23-X-B-II, Estado de Minas Gerais, escala 1:100.000. Brasília, DNPM/CPRM.161p.

Brandalise LA \& Heineck CA (1999) Programa levantamentos geológicos básicos do Brasil. Belo Horizonte, Folha SE.23-Z-CIV. Estado de Minas Gerais. Escala 1:100.000. Brasília, CPRM. $190 \mathrm{p}$.

Coelho RM, Lepsch IF \& Menk JRF (1994) Relações solo-relevo em uma encosta com transição arenito-basalto em Jaú (SP). Revista Brasileira de Ciência do Solo, 18:125-137.

Dossin JA, Dossin TM \& Chaves ML de (1990) Compartimentação estratigráfica do Supergrupo Espinhaço em Minas Gerais: Os grupos Diamantina e Conselheiro da Mata. Rev. Bras. de Geociências, 20:178-186.

EMBRAPA (1997) Sistema brasileiro de classificação de solos. $4^{\mathrm{a}}$ aproximação. Rio de Janeiro, Embrapa. 169p.

EMBRAPA (2006) Sistema Brasileiro de Classificação de Solos. $2^{\mathrm{a}}$ ed. Rio de Janeiro, Embrapa. 412p.

Lemos RC \& Santos, RD dos (1996) Manual de descrição e coleta de solo no campo. $3^{\mathrm{a}} \mathrm{ed}$. Campinas, Sociedade Brasileira de Ciência do Solo. 84 p.

Lepsch IF (1977) Superfícies geomorfológicas e depósitos superficiais neocenozóicos em Echaporã, SP. Boletim Paulista de Geografia, 53:5-34.

Licht OAB (1998) Prospecção geoquímica: princípios, técnicas e métodos. Rio de Janeiro, CPRM. 216p.

Marques EAG (1998) Caracterização geomecânica de um perfil de intemperismo de kinzigito. Tese de Doutorado, Universidade Federal do Rio de Janeiro, Rio de Janeiro. 210p. 
Motta PEF, Carvalho Filho A de, Ker JC, Pereira NR, Carvalho Junior W de \& Blancaneaux, P (2002) Relações solo-superfície geomórfica e evolução da paisagem em uma área do Planalto Central Brasileiro. Pesquisa Agropecuária. Brasileira, 37:869-878

Oliveira AAK, Leite A da S (2000) Projeto Leste: Folha Ipatinga - SE.24-Z-D-II, escala 1:100.000. Belo Horizonte, SEME/ COMIG/CPRM.51p.

Pedrosa-Soares AC, Dardenne MA, Hasui Y, Castro FDC de \& Carvalho MVA de (1994) Nota explicativa dos mapas geológico e metalogenético e de ocorrências minerais do Estado de Minas Gerais - Escala 1:1.000.000. Belo Horizonte, COMIG. 97p.

Perez Filho A, Donzelli JB \& Lepsch IF (1980) Relações solo geomorfologia em várzea do Rio Mogi-Guacu (SP). Revista Brasileira de Ciência do Solo, 4:181-187.

Ribeiro JH (1997) Projeto Leste: Folha Marilac - SE.23-Z-B-VI, escala 1:100.000. v.10. Belo Horizonte, SEME/COMIG/CPRM. $55 \mathrm{p}$.

Ribeiro JH (2000) Projeto Leste: Folha Dom Cavati - SE.24-ZD-III, escala 1:100.000. Belo Horizonte, SEME/COMIG/CPRM $77 \mathrm{p}$

Rodrigues TE \& Klamt E (1978) Mineralogia e gênese de uma sequiência de solos do Distrito Federal. Revista Brasileira de Ciência do Solo, 2:132-139.
SAEG (2007) Sistema para análises estatísticas, versão 9.1. Viçosa, UFV. Aplicativo computacional.

Signorelli N (2000) Projeto Leste: Folha Caratinga - SE.24-Z-DVI, escala 1:100.000. Belo Horizonte, SEME/COMIG/CPRM. $76 \mathrm{p}$.

Silva S da S (2000) Projeto Leste: Folha Coronel Fabriciano SE.24-Z-D-V, escala 1:100.000. Belo Horizonte, SEME/COMIG/ CPRM, 20:71.

Soares Filho BS, Pinheiro S de O \& Costa MN de S (1986) Contribuição ao estudo da geologia da região de Conceição do Mato Dentro (MG) In: XXXIV Congresso Brasileiro de Geologia, Goiânia. Anais, SBG. p.960-973.

Sparovek G, De Jong Van Lier Q \& Lepsch I F (1993) GMAP: Um programa de manipulação de mapas temáticos adaptados a computadores de pequeno porte. O exemplo do município de Piracicaba. Boletim Informativo da Sociedade Brasileira de Ciência do Solo, 18:15-19.

Ubertiv AA \& Klamt E (1984) Relações solo-superfícies geomórficas na encosta inferior do nordeste do Rio Grande do Sul. Revista Brasileira de Ciência do Solo, 8:124-132.

Way DS (1973) Terrain analysis: A guide to site selection using aerial photographic interpretation. Pennsylvania, Dowden, Hutchinson and Ross. 392p. 